chemical technologists. The omission of research from our educational curricula means a loss to our industry of a class of chemical technologist of which we are in needthe man who has been trained in scientific habit of thought by the most effective of all known methods. In advocating the introduction of research into the advanced curriculum it must be most clearly understood that we are not contemplating the "research chemist" as defined in this address. He comes under another category. We are now considering only the higher education of the works chemist and the importance of research in relation to his advanced training. If it is admitted that some advanced training supplementary to the preparatory course is essential, and that science is to form part of that advanced training, the advanced laboratory work from the fourth year onwards could be made to include experimental investigation either in pure or applied chemistry.

The Sphere of the Chemical Technologist.

There appears to be a general opinion in favour of technological training. The proposals come chiefly from the university side, but that is immaterial. All attempts to move in this direction hitherto have been more or less paralysed by the teachers declaring for pure science and by the manufacturers proclaiming that it is impossible to tcach chemical technology in the educational institutions. It is beginning to be perceived that when the technical education of the works chemist is under consideration it is really technological training that is meant. Chemical technology means generalised chemical engineering-a knowledge of the chemical, physical, and mechanical principles underlying the construction and working of the machinery and plant in general use in chemical industry. It is a composite subject, part of which is pure engineering, such as power production and distribution, and part of which is specialised engineering, such as the nature, source, and properties of the materials used in the construction of chemical plant.

There is practically no technical school in this country which provides a complete and coordinated course of training such as I have advocated. For the chemical industries, the technical education movement has been arrested just at that stage where the true technical training should begin. The technical institutions are not wholly, nor for the greater part, to blame; the manufacturers have not sufficiently encouraged them. The greater part of the chemical instruction in the technical institutions is carried on in evening classes. This kind of training is practically useless for industrial chemists. It would take the evening student nine years to complete the three years' preparatory course of the day student. At the same time, evening classes are of real value for men already engaged in the factory work-say foremen and managers who have had no training in scientific theory. After thirty years' technical education applied chemistry is lagging behind all other branches of technology.

The Universities as Schools of Applied Science.

While large numbers of institutions originally intended for instruction in applied science are carrying on purely scholastic courses, the universities, originally academic institutions, are now developing schools of applied science Ought the universities to create departments of applied chemistry? If the ordinary graduate courses were not suitable for the chemical technologist they could be adapted without much difficulty. The university need only make provision for that kind of advanced work which I have advocated. It does not matter what kind of institution does the work so long as it is done efficiently; the need for it is great.

\section{The Conclusion.}

But if the higher work is to be taken over by the universities, the raison d'être of the technical school for chemical industry will become a thing of the past. It will be deplorable and wasteful if we find the university and the technical institution in the same town rivals. instead of colleagues. The rational solution is that the technical institution should become a school of the university, as is the case at Manchester. Such a solution carries with it the implication that the technical institution will raise its technological teaching to the university standard. That is precisely what we want. In framing any educational policy of practical value for our subject the Society of Chemical Industry can play an important part. We are both imperial and international; we have the means of bringing together a body of expert knowledge and experience, both educational and technological, such as is possessed by no other organisation. An advisory or consultative education committee or board formed by our council from the ranks of our members, and comprising teachers and manufacturers, ought to be of such power that no departure in the technical training of chemists in any educational establishment, of whatever rank, could afford to neglect its counsels.

\section{THE CAMPAIGN AGAINST MALARIA.}

M ORE than nine years ago I had the privilege of addressing the Royal Institution (March 2, 1900) on the subject of my researches on the mode of infection in malarial fever, and I am now called upon to describe what has been done, or not done, in various countries to utilise for the alleviation of the disease the information then obtained.

The ancients appear to have recognised, not only the principal symptoms of malarial fever, but the fact that it is often connected with marshes; and more recently many authors ascribed this fact to the existence of poisonous vapours, which they supposed are given off by stagnant waters, or even by the soil. Still later, a series of pathological studies led to the discovery by Laveran in 1880 that the malady is produced by vast numbers of minute protozoal parasites of the red blood-corpuscles, and students of the subiect now conjectured that these organisms originally inhabited the marshes, and infect man through air or drinking-water. My own studies, however, commenced eighteen years ago, and, confirmed and extended by many workers, showed that the parasites are carried from man to man by certain species of Culicida (gnats or mosquitoes) and that it is these carrying agents, and not the parasites themselves, which live in the marshes. Thus malarial fever was now proved to be merely a parasitic disease, the infection of which is carried from man to man by the agency of certain water-breeding insects.

As described in my previous lecture, the broad principles of this theorem were really fully established by the end of the year 1898 . Although numerous minor details still required study-such as the precise species of mosquitoes which carry the infection in various countries, the exact habits of each species, and so on-yet I held that these questions could now be elucidated without difficulty in the ordinary course of work, and that we were already in a position to apply the discovery at once to the saving of human health and life. I propose, therefore, to take up the story again from this point.

First let me emphasise the great importance of this practical side of the subject. Malarial fever is spread over nearly the whole of the tropics, abounds in many temperate climates, and has been known to extend so far north as Sweden. In vast tracts of tropical Africa, Asia, America, and southern Europe almost every town and village is infested by it; millions of children suffer from it from birth to puberty; and native adults, though they tend to become partially immune, still remain subiect to attacks of it. Although it is not often directly fatal, yet it is so extremely prevalent, so endemic in locality, so persistent in the individual, that the total bulk of misery caused by it is quite incalculable. More than this, its special predilection for the most fertile areas renders it economically a most disastrous enemy to mankind. Throughout tropical life it thwarts the traveller, the missionary, the planter, the soldier, and the administrator. From one-quarter to one-half the total admissions into military hospitals are returned as being due to it, and it is often the most formidable foe which military expeditions have to encounter. There are reasons for thinking that it indirectly increases the general death-rate of malarious countries by something like 50 per cent., and I venture to say that it $h$ is pro1 Discourse delivered at the Royal Institution on Friday, May 7, by Prof. Ronald Ross, F.R.S.

No. 2066, voL. 8o] 
foundly modified the history of mankind by doing more than anything else to hamper the work of civilisation in the tropics. Only those who have studied the disease from house to house, from village to village, can form any true notion of the total effect which it must produce throughout the world.

Next let us recall briefly the various methods which we possess for preventing and reducing the disease. The oldest of these--known to us since the time of the Romans -is drainage of the soil. The reason why it succeeds became quite obvious after 1898 -because it tends to remove the terrestrial pools and marshes in which the Anophelines, that is, the family of mosquito which carry malaria, breed; but the new discoveries not only explained the old method, but also rendered it more simple, cheap, and yet -precise, by showing us exactly what waters, namely, those in which the larvæ of the Anophelines actually occur, are to be drained away, or filled up, or otherwise treated. But science has given us other methods as well. Thus we have known for a long time that quinine is a preventive as well as a cure-that if, for cxample, a body of men are given quinine with regularity they will sulfer less from fever in consequence. Still further, the old saying that the use of mosquito-nets at night will keep off malaria was now fully justified, not because the nets exclude any aërial poison, but simply because they exclude the infecting insects. This simple precaution can, moreover, be extended by protecting. all the windows of a house by wire-gauze, as already frequently done in the southern States of America. Punkas and electric fans also serve to keep away the insects; and, lastly, segregation of Europeans from native quarters, as used so largely in India, will help to keep them from mosquitoes infected by native children (who suffer so frequently from the disease). It was thus apparent that if the inhabitants of malarious countries could be persuaded to protect themselves by mosquito nets or quinine, or if the Governments of such countries could be persuaded to undertake suitable drainage and other measures against mosquitoes, much improvement in the public health was likely to accrue.

But how precisely was such persuasion to be undertaken? Of course, I do not allude to utterly barbarous peoples, to areas far beyond the influence of civilisation, which are happily shrinking in magnitude every day. I allude to independent or dependent States professing themselves civilised, and to the numcrous colonies of the great civilised nations. Here we already possess the requisite machinery. Such States or colonies are administered by governors and councils, and for the most part possess medical and sanitary departments controlled by well-paid officials, whose special duty it is to attend to such affairs. Many dependencies, moreover, such as some of these of Britain, are placed under the central Government of the nation concerned, and can be influenced by it. It might be supposed, then, that at the period referred to all such udministrations would have gladly interested themselves in the prevention of a disease which produces so much mischief, and of which the cause had been so clearly elucidated; that they would at once have set about collecting preliminary information, and commencing at least some experimental trials. So far as I can see, there is no real reason why this was not done everywhere nearly ten years ago.

Unfortunately, though science may provide us with facts, humanity is slow to credit them, and still more slow to take advantage of them. History is full of examples of this. For instance, years elapsed before the discovery of Jenner was fully utilised-it is not fully utilised even yet. Another instance, closely connected with malaria, is that of filariasis, a parasitic disease of which elephantiasis is one manifestation. More than thirty years ago very good evidence was given to show that it is carried by mosquitoes, and, considering the horrible and widespread deformities which it produces, one would have thought that strong efforts would have quickly been made to control it by reducing the carrying agents. So far as I can ascertain. however, scarcely anything has yet been even attempted against:it. No one has interested himself seriously in the matter, and consequently nothing has been done.

It was therefore early apparent to me that, though the No. 2066, VGL. Sol machinery for extensive anti-malarial work existed in many countries, yet it would not easily be got to work unless someone could be found who would devote himself to the task-neither a pleasant nor a profitable one-of urging it forward, and I felt that the duty devolved on myself, in the absence of others, as regards British territory. Happily, Angelo Celli and Robert Koch occupied themselves similarly as regards Italy and Germany, and the creation of the Schools of Tropical Medicine in Liverpool and London in 1899 did much to popularise the recent discoveries. At my inaugural lecture the same year, at the former institution, I described my proposals for the prevention of malaria by mosquito reduction, and a few months later, accompanied by Dr. H. E. Annett and Mr. E. E. Austen, I left England for Sierra Leone in order to perfect the details.

Sierra Leone is a small British colony long notorious for its extreme unhealthiness. We determined rapidly the malaria-bearing species of Anophelines there, and their breeding places and habits, and drew up a series of proposals for their reduction. These have since become the basis of similar work elsewhere; but, simple as they were. we could not get the local authorities to understand them or act upon them. 'Two years later I again-twice-visited the colony, and, assisted by Dr. Logan laylor and a sum of money presented to me for the purpose by a private gentleman, attempted to give an object-lesson on the sub. ject. Though the result was successful at the time, we again failed in inducing the authorities to take up the work properly; and I can obtain no adequate information as to what has been done there during the last seven years, and may perhaps be excused for not wishing to inquire.

In the meantime, the Liverpool School of Tropical Medicine and the Royal Society had sent a series of expeditions to West Africa, which did much good work there. As a consequence, Sir William MacGregor, Governor of Lagos, and one of the most enlightened of British administrators, took up the task in that colony with great intelligence and energy, but, unfortunately, was shortly forced to leave by ill-health-a serious blow to anti-malarial work throughout the world. From that time, though much appears to have been done by energetic individuals in Wcst Africa, and though, to judge from popular statements, public health has been decidedly improved there, yet the official reports and returns are too inadequate to enable us to form any trustworthy opinion of the results. The recent statements of Prof. Simpson on the subject are not encouraging; and to my mind, judging from many facts known to me, the sanitary administration of the West African colonies has been generally wanting in leadership and organisation, and the campaign against malaria has been constantly thwarted by administrative indifference and professional jealousy.

Turning elsewhere, I must now mention with great pleasure the early and successful campaign of Koch at Stephensort, in New Guinea. The method of Koch does not depend on mosquito reduction, but on the detection and treatment of cases of malaria by quinine, until they cease to spread the disease among their healthy neighbours. It is allied to the similar method used in other diseases, has been successfully followed in the German colonies and in Italy, and will always be a valuable weapon in the antimalarial armoury. The great work of Celli and the Italian Anti-malaria Society, commenced early in 1899 , has been based on the same, but also on a wider, principle of distribution of quinine, together with mechanical protection from mosquito bites. Working onward step by step against political and local indifference, they have gradually made, during the last ten years, a great reduction in the amount of the disease throughout Italy. An independent witnessProf. Osler-has recently written as follows to the Times :"In Prof. Celli's lecture-room hangs the mortality chart of Italy for the past twenty years. In 1887 malaria ranked with tuberculosis, pneumonia, and the intestinal disorders of children as one of the great infections, killing in that year 21,033 persons. The chart shows a gradual reduction in the death-rate, and in 1906 only 4871 persons died of the disease, and in $1907,4160 . "$ I should be unable to hang a similar chart for British possessions in my lectureroom.

In 1900-I a great discovery, closely connected with our 
subject, was made by the Americans in Havana-I mean the discovery that yellow fever, the scourge of tropical America, is also carried by mosquitoes of the kind called Stegomyia. With the Americans, however, there was no delay in turning this fact to practical account, and under General Wood and Colonel Gorgas they got rid of the disease from that large city in a few months. Since then Colonel Gorgas has been conducting the magnificent sanitary work of the Americans in the Panama Canal zonework the success of which is too well known to require illustration by figures, but which has enabled the Americans to do what the French, before the date of these discoveries, failed in doing, namely, to continue the construction of the canal. It is not too much to say that the canal is being made with the microscope. Colonel Gorgas has repeatedly stated that the measure upon which he principally relies, against both yellow fever and malaria, is the general reduction of mosquitoes.

For three years my original proposals to remove malaria by this means had not been thoroughly and formally applied by any Government, but I have now to record the first classical successes obtained by it in Ismailia and in the Federated Malay States. The former is a town founded by Ferdinand de Lesseps on the Suez Canal. For many years it had suffered extremely from malaria, the cases amounting ultimately to about 2000 a year among a small population. In I902 I was asked by Prince Auguste d'Arenberg to advise on the matter, and my advice was acted upon loyally and intelligently by his officers in the town. The result was that the cases fell to 214 next year and to ninety in 1904, and that since then there has been no endemic malaria in the town at all, while mosquitoes of all kinds have been practically banished from it. The work in the two small towns of Klang and Port Swettenham, in the Federated Malay States, was begun about the same time, chiefly by Dr. Malcolm Watson under the orders of the Government and of Dr. E. A. O. Travers, and has been equally successful. No one who has studied the facts published with regard to both these campaigns can for a moment deny the success obtained.

Since then excellent campaigns on similar lines have been conducted at Durban, Hong Kong, Khartoum, Candia, and St. Lucia. Most striking has been the anti-mosquito work conducted at Port Said under the orders of Sir Horace Pinching, recently head of the Egyptian Sanitary Service, by my brother, Mr. E. H. Ross. The town has been so completely cleared of mosquitoes that, as at Ismailia, the ladies no longer use mosquito nets for their children. I may add that I have just recently visited both localities, and was able to verify this statement by conversations with a number of people. Fuller accounts of some of these campaigns will be found in a paper by me published in the Lancet of September 28, 1907. Excellent and extensive work has been done for many years in Algeria by Drs. Edmond and Etienne Sergent (Annales de l'Institut Pasteur, 1909) by all methods, and by Drs. Savas and Kardamatis and the Greek Anti-malaria League (Annals of Tropical Medicine and Parasitology, Liverpool, June, 1908). The Italian work is published in the Atti della Società per gli studi della Malaria, and Dr. Laveran gives much information on the subject in his last book on malaria, "Du Paludisme," r907.

Two vears ago I was asked by the Government of Mauritius to advise regarding malaria in that ancient island colony. The War Office associated Major C. E. P. Fowler, R.A.M.C., with me, and after three months' studies, warmly assisted by the Governor, the officials, the planters, and everyone, we drew up our scheme for a general campaign against the disease. There is no doubt that this scheme will be followed when the present financial situation is rectified, but in the meantime I hope and trust that our reports, which were written with great care, and have been published by the Colonial Office and the War Office respectively, will prove of value in other parts of the tropics.

When I left India in 1809 I hoped that that great dependency of the British Crown, with its powerful Government and well-appointed medical and sanitary services, would lead the way against malaria, a disease which causes untold sickness, and possibly some millions of deaths, annually in the country: but though many local No. 2066, VOI. 80 campaigns have been started by individual medical men, and though there has been a steady fall in the malaria rate of the army, I can find no evidence of a generalised effort against the disease. Less than three months ago I attended the Medical Congress at Bombay, largely for the purpose of inquiring into the reason for this, and concluded that though many capable officers, both of the Indian Medical Service and of the Royal Army Medical Corps, had done their best, yet the necessary leadership and organisation were wanting in India as in West Africa. An ill-judged and ill-conducted experiment at Mian Mir has done much to paralyse all efforts in this direction, and I gathered that anti-malarial campaigns were not popular among certain officials. Neither the Indian Government nor the medical services can be congratulated on the result.

Some years ago the Secretary of State for the Colonies issued a circular to the Governors of Crown Colonies asking for information as to what had been done in each against malaria and other mosquito-borne diseases, and statements on the matter from twenty-one colonies were published in the Report of the Advisory Committee of the Tropical Diseases Research Fund for 1907. I have criticised these statements in detail elsewhere. Only those furnished by seven colonies, namely, Southern Rhodesia, Papua, Mauritius, British Central Africa, Gambia, Ceylon, and Southern Nigeria, showed evidence of any real interest in the matter. Those from Bahamas, Barbadoes, Jamaica, and St. Kitts-Nevis showed, to my mind, nothing but neglect of public duty, while those from Northern Nigeria, St. Lucia, British Honduras, Grenada, Somaliland, Straits Settlements, and Sierra Leone gave no decisive evidence of the reverse.

For a number of years I have had very good opportunities of learning the truth as to what is really being done in many of these and other dependencies. It may generally be summed up in two words-very little. Festering pools which might have been cleared years ago for a few shillings or pounds are left in the heart of important towns to poison all around them; quinine prophylaxis is neglected, and house-screening forgotten. No efforts are made even to estimate the local distribution of the disease, much less to organise any serious efforts against it, although it may be causing, perhaps, half the sickness in the place.

Want of funds is always an excuse which is urged-and is always a false excuse. Much can be done at almost no expense; and the men who have actually carried out the work successfully in Panama, Ismailia, the Federated Malay States, and Italy have expressly declared the cheapness of it. Many a town could be kept clear of malaria for the amount, say, of the salary of a single European official. I estimate that a sixth of the medical and sanitary budget should generally suffice to reduce a disease which often causes half the sickness; but instead of doing really useful work which would benefit everyone, the authorities too often fritter away their funds on trifling schemes. I maintain that the health of the people has the first claim on the public purse.

Another excuse is that the possibility of preventing malaria has not been proved, but when one questions the sceptics one generally finds that they have not troubled to study the literature.

The fact is that the neglect of which I complain is due to quite other causes. I do not think that, as a rule, the blame is to be attached to the rank and file of the medical profession in the tropics. Men on the clinical side generally have enough to do with their hospitals and medical practice, while those on the sanitary side frequently complain that their recommendations are not seriously attended to. The immediate responsibility lies with the heads of the sanitary services of the colonies - men who are specially paid to organise such work. Now, though many capable individuals are to be found in such medical services, there is always a percentage of men, in them as in other services, who, to be frank, are not at all capable-men who from the date of receiving their medical qualifications take no further real interest in their work, read no literature, undergo no further courses of instruction, undertake no scientific researches, and make no additions to our knowledge either of medicine or of sanitation, and yet who manage to obtain the highest medical or sanitary appointments, either by seniority or by the well-known arts of 
self-service and wire-pulling. I am sorry to have to express such an opinion, but I think that this type of person is much too common in all branches of British administration. Worse heads of departments cannot be found. They scoff at the knowledge and efforts of others in order to cover their own ignorance and apathy. To them all new discoveries are frauds, and all new proposals are charlatanism. They repress every kind of honest endeavour among their juniors; they fill the best appointments with their own friends; and they truckle to their official superiors in the hope of obtaining further preferment. At last, decorated and pensioned, they leave the field to others of their own stamp-men without an idea or an ideal, except such as refer to their own advancement. These are the persons who are really responsible for the state of things which I have described.

As a rule, colonial Governments are far too careless in the selection of the men to whom they entrust the health of the public. It is openly said that they often choose either mediocrities or men who they know will be too subservient to them to assert the demands of sanitation-which is never a popular theme. At home, no one may be the medical officer of health, even of an English village, without possessing a proper diploma entitling him to practise as such; but it appears that anyone is good enough to be the chief sanitary officer of a whole country. The most amazing appointments are often made. Men of known and approved ability are passed over in favour of others who are supposed to possess special administrative qualifications, which frequently means nothing but a capacity for selfadvancement, and both senior and junior sanitary officers complain that their representations regarding anti-malaria work often receive no intelligent attention either from the civil or the military authorities.

Root-and-branch reforms are required in all these respects. The failure of most of our tropical dependencies during ten long years to understand and act upon modern discoveries in connection with malaria, and indeed, with other diseases, demonstrates that their sanitary services no longer fulfil the purpose for which they are paid and appointed. Reconstruction, similar to that which has revivified the Royal Army Medical Corps, is urgently dernanded. It is not too much to ask that no man shall be appointed to an administrative post without previous examination as to his fitness-that no man shall be entrusted with the post of chief sanitary officer unless he can show evidence of having really worked at the subject, of having mastered scientific details, and of having obtained the qualifying diplomas of public health and tropical medicine. He should be placed on the Executive Council, which is now so frequently managed by the heads of less important departments. Proper arrangements should be made for expert inspection and supervision, and much more science, work, and discipline should be demanded, not only in the services, but in those who control them.

I have now outlined the general course of events. The immediate success which we had hoped for ten years ago has not been attained. The battle still rages along the whole line; but it is no longer a battle against malaria. Malaria we know, we understand fully, we can beat down when we please. The battle which we are now fighting is against human stupidity. Those of us who have taken part in it-not too numerous-know what it has been. We have written and lectured ad nauseam; we have interviewed ministers, members of Parliament, and governors; we have appealed to learned societies; we have sought the support of distinguished people; and we have received-sympathy. We have reasoned, and been ridiculed; we have given the most stringent experimental proofs, and been disbelieved; we have protested, and been called charlatans. I think that not one of those young men who have pioneered this important work in the field has ever received thanks for his labours. On the other hand, I know of several who have been actually punished for it. I know that all new movements have to face opposition of this kind: but surely the world is becoming too old for it. We talk much of science, and collect funds for research and teaching, and hold conferences and congresses, and blow trumpets over our doings; but when a useful discovery reallv is made, when the cause and methods of prevention of the most important of human diseases have been discovered, taught, and tried for ten years, this is the way we employ it for the good of humanity! Of what use is it to make discoveries if, when they are made, they are neglected? Remember that all this time, while we are questioning facts that are proved and methods that are established, hundreds of thousands, nay millions, of poor people are suffering from our dullness. I conclude with an appeal. The matter must be taken up in Parliament and in the Press as vigorously as possible. If some of the officials at fault could be persuaded to accept their pensions and decorations before the usual time, room might be made for more capable men. The few persons who have fought the fight and failed are scarcely able to continue it. If no stronger influences can be exerted, the future of malaria prevention in British dominions will certainly be as barren as the past has been.

\section{UNIVERSITY AND EDUCATIONAL} INTELLIGENCE.

Camiridge.-It is proposed, in connection with the Darwin centenary, to confer the degree of Doctor of Science, honoris causa, upon the following:-Otto Bütschli, professor of zoology in the University of Heidelberg; Richard Hertwig, professor of zoology in the University of Munich; Hermann Graf zu Solms-Laubach, professor of botany in the University of Strassburg; F. Vejdovský, professor of zoology in the Bohemian University of Prague; and Max Verworn, professor of physiology in the University of Göttingen.

During the long vacation the science courses will include the following:-the curator of the herbarium, Mr. C. E. Moss, will give a series of demonstrations and lectures on systematic botany (flowering plants) in the botany school, beginning Tuesday, July 6 . Weekly excursions will be arranged in connection with the lectures and demonstrations. Mr. K. J. J. Mackenzie will conduct classes on the University farm for a month, beginning on July 6 . The classes are specially designed for students who have passed the natural sciences tripos, part i., and propose to take the diplona in agriculture. Dr. Fenton will give a course of fifteen lectures on the outlines of general chemistry on Tuesdays, Thursdays, and Saturdays. These lectures will begin on July 6 .

THE directorship of the Harvard Botanical Garden, which recently became vacant through the resignation of Prof. Goodale, as reported in our issue of May 13, has been filled by the appointment of $\mathrm{Mr}$. Oakes Ames, assistant professor of botany.

Commemoration Day was celebrated at Livingstone College, Leyton, on May 26. The college provides a medical training for missionaries, since the medical part of a missionary's work is now considered of prime importance. During the course of an address, Prof. Alexander Macalister said he had confidence in the course of training given at the college, and from his experience in Syria and China he believed it was essential that a missionary should be able to render simple medical aid to natives, and he hoped before long some such training would be regarded as an absolute necessity for every missionary. Dr. M. A. Stein, in the course of a short speech, referred to the valuable surgical aid he had received from an old student of Livingstone College during his explorations in Central Asia.

FROM July 6 to July 28 short courses of instruction for science teachers will be given at the Imperial College of Science and Technology, South Kensington, London, S.W. in chemistry, light, mechanics, plant physiology, and practical mathematics. Any teacher who wishes to attend one or other of the courses should apply at once for form of application (Form 50I T) to the Secretary, Board of Education, Whitehall, S.W. The courses are limited to the teachers of classes in science, and in considering applications for admission the Boatd will have regard to (x) the character of the work done in the class or classes taught by the applicant and the probability of extension of this work; (2) the qualifications of the applicant as showing the extent to which his previous training will enable him to profit by the instruction given.

No. 2066, vor.. 80] 